\title{
Restorative proctocolectomy with end to end pouch- anal anastomosis in patients over the age of fifty
}

\author{
W G Lewis, P M Sagar, P J Holdsworth, A T R Axon, D Johnston
}

\begin{abstract}
This study was to examine whether 'fit' patients over the age of 50 who require elective surgery for ulcerative colitis are suitable candidates for restorative proctocolectomy, providing that they are continent before operation and that the anal sphincter is preserved in its entirety without stripping of the mucosa or endoanal anastomosis. Between 1986 and 1991, 18 patients 50 to 66 years old (median 55 years: nine men) underwent restorative proctocolectomy with end to end ileoanal anastomosis without mucosal stripping (12 quadruplicated $(\mathbf{W})$, four duplicated $(J)$, two no reservoir). The results were compared 12 (range three to 24) months later with those of 18 matched patients who were less than 50 years of age (median 34 years). In patients over 50 , median resting anal pressure was 88 (range $44-131) \mathrm{cm}$ water before and $80(47-138) \mathrm{cm}$ water after the operation (NS). In patients under 50, median resting anal pressure was 76 (51-128) $\mathrm{cm}$ water before and 77 (36-137) cm water after operation (NS). Resting anal pressure in older patients did not differ significantly from that in younger patients either before or after the operation. Both sensory and reflex anal functions were preserved as well after operation in the older patients as in the younger ones. The clinical results in patients over 50 were slightly inferior to the results for the younger patients, but the difference was small and not significant. Hence age alone is not a contraindication to restorative surgery provided that the anal sphincter is preserved in its entirety.

(Gut 1993; 34: 948-952)
\end{abstract}

Restorative proctocolectomy is the procedure of choice for most patients who require surgical treatment for ulcerative colitis. As experience with the procedure has increased a wide range of functional results has been reported; some patients achieve virtually normal bowel function, whereas a few suffer from urgency and frequency of defecation and even incontinence. This in turn has led clinicians to try to identify the factors that might be responsible for poor clinical results. In the large Mayo clinic series of pelvic J reservoirs with mucosal proctectomy, mean bowel frequency was 11 in 24 hours in patients over 50 years of age compared with seven in 24 hours in patients under 50, a statistically significant and clinically important difference. Although the age of the patients did not correlate with their ability to achieve continence after operation, the greater the number of stools, the more often were the patients incontinent. Findings such as these - together with considerations of operative risk to life - have tended to limit the use of restorative proctocolectomy to patients who are less than 50 years of age.

We showed previously that two factors were of critical importance if a good clinical result were to be achieved after restorative proctocolectomy: firstly, the pelvic reservoir should be capacious and compliant and should empty well; secondly, the anal sphincter must be strong both before and after operation. ${ }^{23}$ The second objective was best served, in our experience, by leaving the anal sphincter intact at operation without any stripping of anorectal mucosa and without endoanal anastomosis. ${ }^{4}$ We wondered whether, if these criteria were satisfied, the benefits of restorative proctocolectomy might be extended to older patients. In this paper we describe the results of restorative proctocolectomy in 18 patients over the age of 50 whom we have treated in the past six years and compare them with the results achieved in younger patients. This is a retrospective study.

\section{Patients and methods}

Between 1986 and 1991, 18 (18\%) patients out of a total of 100 who underwent restorative proctocolectomy were aged 50 years or over (median 55 years, range 50 to 66 years). Nine were men. Each patient underwent restorative proctocolectomy, the pelvic reservoir or ileum being anastomosed end to end to the anal sphincter without any stripping of the anal mucosa. We have described the technique employed in detail. ${ }^{5}$ Twelve patients had quadruplicated (W) ileal reservoirs, ${ }^{6}$ four had duplicated $(\mathrm{J})$ reservoirs, ${ }^{7}$ and two patients underwent straight ileoanal anastomoses. A group of 18 patients aged 16 to 41 years (median 31 years), who had also undergone restorative proctocolectomy, matched for sex, type of reservoir, operative technique, and duration of follow up formed a control group for comparison with the older patients (Table I). This control group represents a consecutive 18 patients chosen at random from a period midway through our experience in 1987 to 1989 , who are typical of patients presenting

TABLE I Details of the two groups of patients

\begin{tabular}{lll}
\hline & \multicolumn{2}{l}{ Age } \\
\cline { 2 - 3 } Patients & Over 50 & Under 50 \\
\hline No & 18 & 18 \\
Age (y) (median (range)) & $55(55-66)$ & 31 (16-41) \\
Sex & $9 \mathrm{Men}$ & $5 \mathrm{Men}$ \\
Reservoir & $12 \mathrm{~W}$ & $12 \mathrm{~W}$ \\
& $4 \mathrm{~J}$ & $4 \mathrm{~J}$ \\
Ulcirative colitis & $2 \mathrm{None}$ & $2 \mathrm{None}$ \\
Follow up (months) (median (range)) & 18 & 18 \\
& $12(3-24)$ & $12(6-15)$ \\
\hline
\end{tabular}


for elective operation for ulcerative colitis. The selection criteria used were the same for all patients - namely, each patient was individually assessed with respect to general fitness for operation. Anal sphincteric function was then assessed quantitatively in our physiology laboratory. The same physiological selection criteria for operation were used for young and old patients alike. In simple terms, provided the patient with colitis was clinically continent, we found that this was invariably accompanied by satisfactory physiological results. All patients who expressed a desire to undergo a sphincter preserving operation were found to have satisfactory anal sphincter pressure and anal canal sensation, and therefore to date we have not rejected any patients simply on the grounds of age and inadequate sphincter function on testing.

\section{LABORATORY STUDIES}

Each patient underwent studies of anal sphincteric function before operation and a median of 12 months (range 3-24 months) after operation. Figure 1: Maximum resting anal pressure $(R A P)$ before and after operation. Median and interquartile range. There were no significant differences.
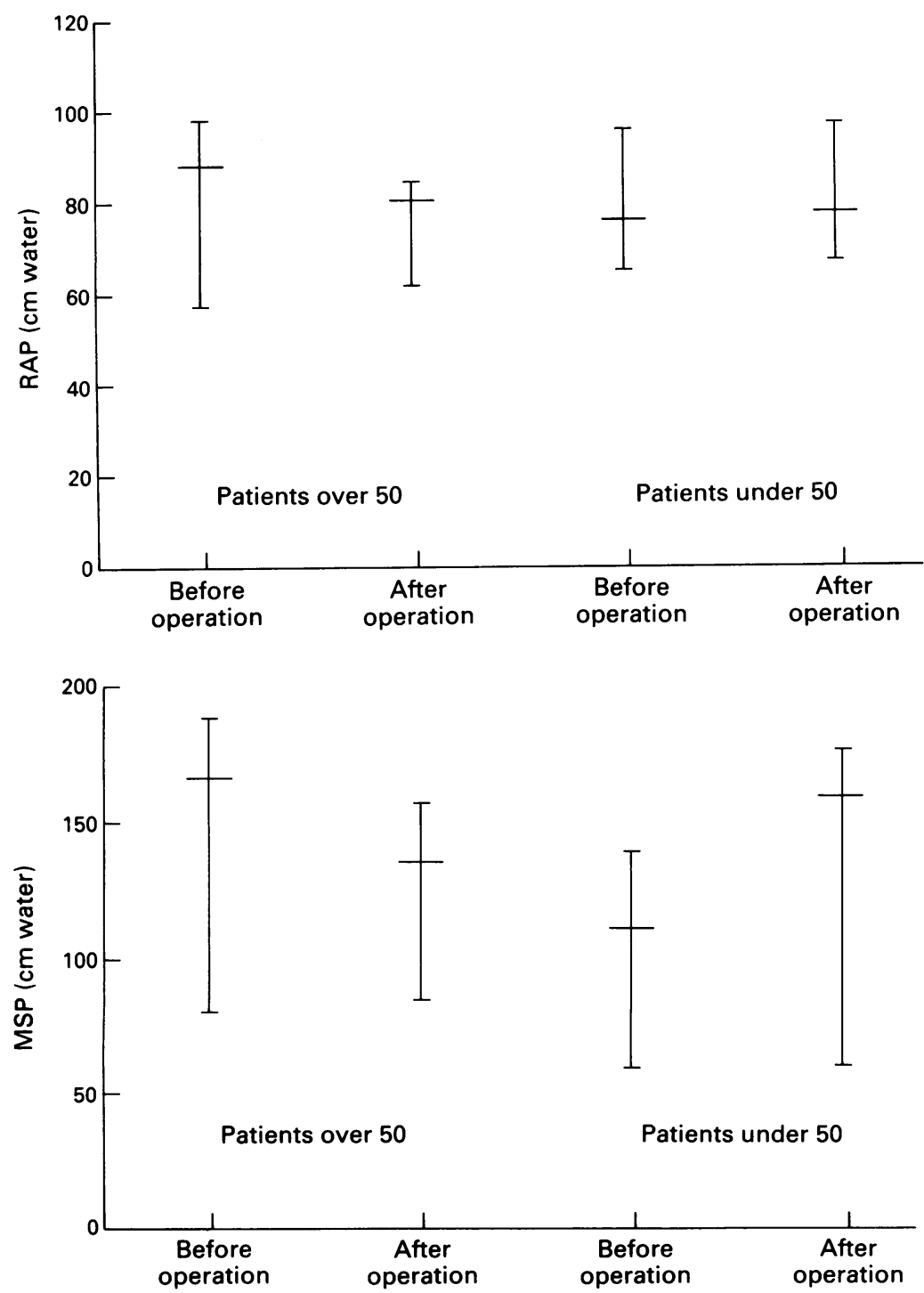

Figure 2: Maximum squeeze pressure (MSP) before and after operation. Median and interquartile range. There were no significant differences.
Sensation was tested by measuring threshold electrosensitivity of the anal mucosa by means of a bipolar constant current stimulator probe, lubricated with a solution of KY Jelly (Johnson and Johnson, Ascot, Berks, UK) and normal saline in equal quantities. ${ }^{8}$ The rectoanal inhibitory reflex was assessed by inflating a balloon situated in the pelvic reservoir with air and measuring the response of the anal sphincter to distension of the reservoir: a $20 \%$ decrease in anal pressure was taken to denote a positive reflex. ${ }^{9}$

\section{CLINICAL ASSESSMENT OF OUTCOME}

The quality of anal continence was assessed clinically by two doctors who questioned each patient about faecal leakage by day and during sleep, the need to wear a pad, anal soreness, the ability to defer defecation for longer than 15 minutes, and the ability not only to discriminate between flatus and faeces but to release flatus safely without having to visit the lavatory. This assessment took the form of a standard preconstructed quality of life questionnaire that was presented to the patients a median of 12 (three to 24) months after operation. All patients routinely underwent clinical assessment of continence before operation.

\section{STATISTICAL ANALYSIS}

All grouped data were expressed as median and range. The groups were compared by means of the Wilcoxon matched pairs signed rank test for paired data and the Mann-Whitney $U$ test for unpaired data. Nominal data were analysed with Fisher's exact test. ${ }^{10}$

\section{Results}

\section{ANAL SPHINCTER PRESSURE}

In patients over 50, median maximum resting anal pressure was $88 \mathrm{~cm}$ water (range 44-131) before operation and $80 \mathrm{~cm}$ water (range 47-138) after operation (NS). In patients under 50, median maximum resting anal pressure was 76 $\mathrm{cm}$ water (range 51-128) before operation and 77 cm water (range 36-137) after operation (NS). Resting anal pressure in older patients did not differ significantly from that in younger patients, either before or after operation (Fig 1).

In patients over 50, the median maximum squeeze pressure was $167 \mathrm{~cm}$ water (range 68240) before operation and $135 \mathrm{~cm}$ water (range 58-233) after operation (NS). In patients under 50 , the median maximum squeeze pressure was $120 \mathrm{~cm}$ water (range 58-240) before operation and $171 \mathrm{~cm}$ water (range 58-291) after operation (NS). The maximum squeeze pressure in older patients did not differ significantly from that in younger patients, either before or after operation (Fig 2).

PRESSURE PROFILE OF THE ANAL SPHINCTER

Figures 3 and 4 show the pressure profiles of the anal sphincter before and after operation in the two groups of patients. The profile of the 


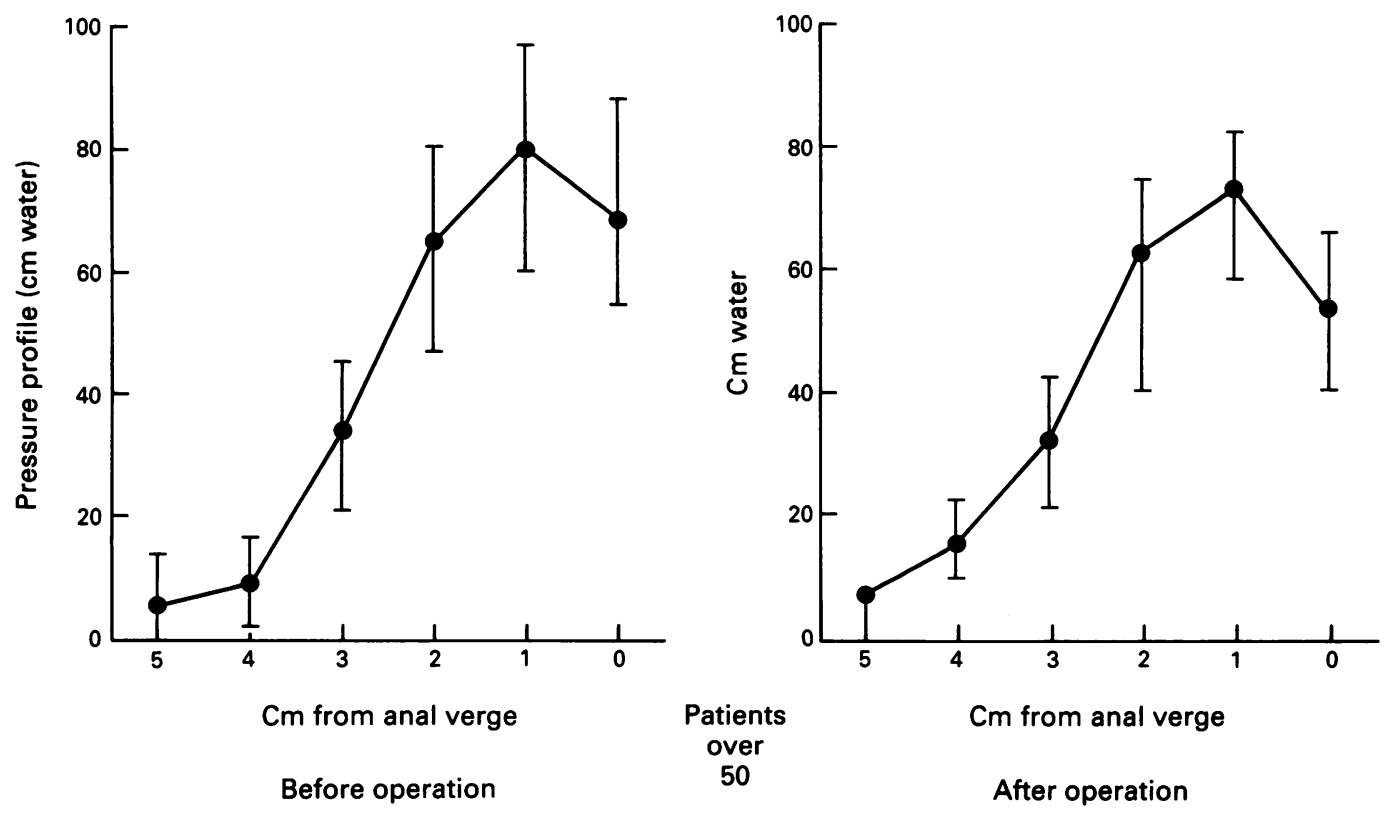

Figure 3: Sphincter pressure profile by the station pull through technique before and after operation in patients over 50. Median and interquartile range. There were no significant differences in pressure at each of the points measured in the anal canal.

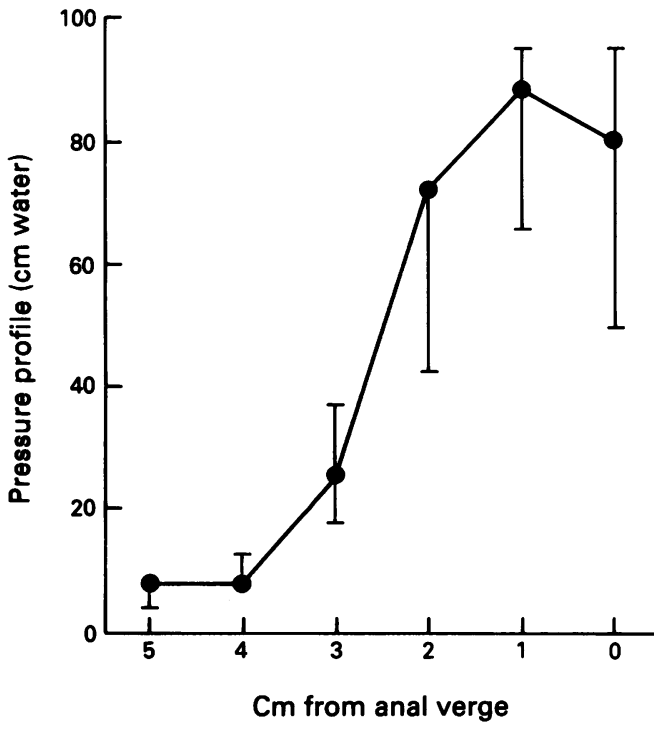

Before operation

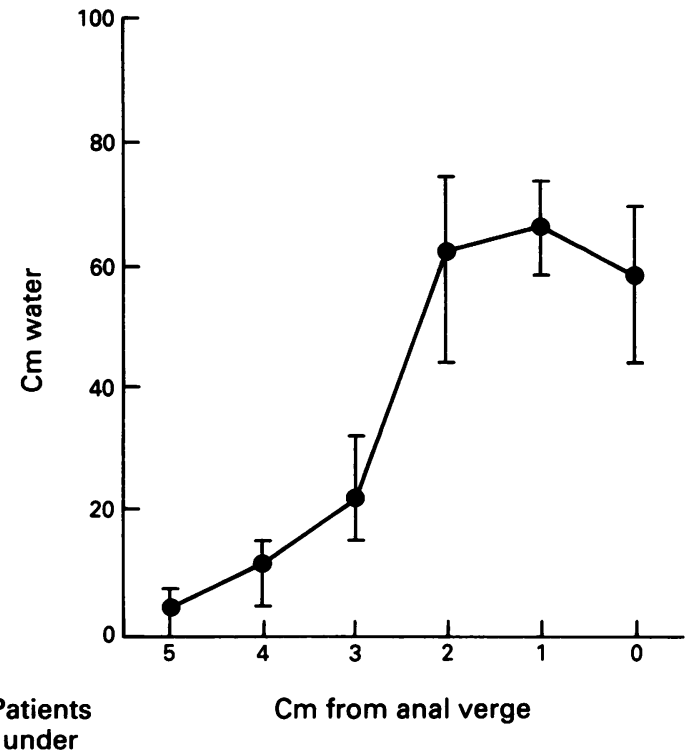

After operation

Figure 4: Sphincter pressure profile by the station pull through technique before and after operation in patients under 50. Median and interquartile range. There were no significant differences in pressure at each of the points measured in the anal canal.

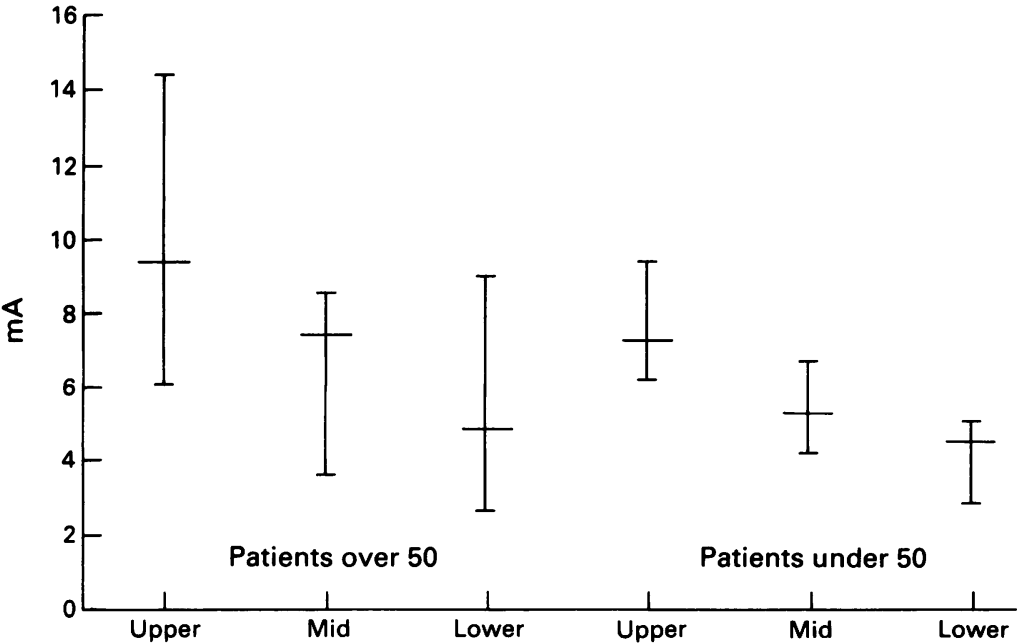

Anal canal level

Figure 5: Anal canal sensation after resorative proctocolectomy assessed by mucosal electrosensitivity. Median and interquartile range. There were no significant differences. sphincter after operation did not differ significantly from the profile before operation in either group of patients. Also, the sphincter pressure profile before operation in patients over 50 did not differ significantly from the profile before operation in patients under 50: nor did the pressure profiles of the two groups after operation differ significantly.

SENSATION IN THE ANAL CANAL

The thresholds for sensation in the upper, mid, and lower anal canal after operation did not differ significantly from the thresholds for sensation at these sites before operation as determined by mucosal electrosensitivity. When sensory thresholds in patients over 50 were compared with sensory thresholds in patients under 50, no significant difference was found either before or after operation (Fig 5). 
TABLE II Clinical results

\begin{tabular}{lll}
\hline & \multicolumn{2}{l}{ Age } \\
\cline { 2 - 3 } Patients & Over 50 & Under 50 \\
\hline No & 18 & 18 \\
$\begin{array}{l}\text { Bowel frequency in 24 hours (median } \\
\text { (range)) }\end{array}$ & $5(2-9)$ & $4(2-9)$ \\
$\begin{array}{l}\text { Mucus leakage } \\
\text { Minor faecal leakage }\end{array}$ & 5 & 3 \\
Defer defecation longer than 15 minutes & 14 & 0 \\
Discriminate flatus from faeces & 12 & 17 \\
Clinical failure & 0 & 0 \\
\hline
\end{tabular}

^For precise definition of 'discrimination', see patients and methods section.

There were no significant differences between the two age groups.

RECTOANAL INHIBITORY REFLEX

The reflex was present in all patients before operation. After operation it was present in 13 patients over 50 and in 15 patients under 50 years of age (NS).

\section{CLINICAL RESULTS}

Table II summarises the clinical results. The functional outcome in patients over 50 was slightly but not significantly inferior to the outcome in the younger patients. Six patients over the age of 50 experienced minor leakage whereas only three patients under the age of 50 experienced such leakage. In five of these six patients the leakage consisted only of mucus. Only one patient experienced minor faecal leakage and even that was not severe enough to necessitate the wearing of a pad. Most patients in both groups could defer defecation for longer than 15 minutes (usually for much longer periods) and could discriminate satisfactorily between flatus and faeces.

\section{Discussion}

The introduction and subsequent evolution of restorative proctocolectomy over the past 14 years has meant that most patients who require surgical treatment for chronic ulcerative colitis are no longer condemned to life with a permanent ileostomy. Also, a perineal wound is avoided entirely and it is rare for pelvic autonomic nerves to be damaged. It is widely assumed that restoration of intestinal continuity inevitably results in a better quality of life for the patient, but that is not necessarily the case. For example, if the patients' bowels act too often or with great urgency, and especially if there should be repeated episodes of faecal leakage or even frank incontinence, they might be better off with an ileostomy. Hence the report from the Mayo clinic that after mucosal proctectomy with a pelvic J reservoir and endoanal, pouchanal anastomosis, bowel frequency in patients over 50 years was 11 in 24 hours, compared with seven in patients under 50 years' and the fact that about $50 \%$ of all patients experienced minor faecal leakage in the first year after operation, discouraged the use of restorative proctocolectomy in older patients in whom the operative risk must also be assumed to be greater. That report from the Mayo clinic was mirrored to some extent by the study of Pescatori and Mattana ${ }^{11}$ who reported that $45 \%$ of patients over the age of 45 experi- enced faecal soiling, whereas only $24 \%$ of patients under 45 years of age did so. These authors also reported that when bowel frequency increased to more than five evacuations in 24 hours, irrespective of the patient's age, the incidence of faecal soiling increased from $20 \%$ to $48 \%$. Such imperfections of bowel function obviously result in a poorer quality of life for the patients concerned, suggesting that the price paid for avoidance of a permanent ileostomy may be too high in older patients.

The effect of age on anorectal function in normal people has been investigated previously..$^{12}$ Mean maximal resting anal pressures and maximum squeeze pressures were significantly lower in older people, although the word 'older' referred to patients over the age of 65 rather than 50 as in this study. In patients with longstanding ulcerative colitis, any tendency for the anal sphincter to weaken with age may be counterbalanced by the effect of work hypertrophy on the anal sphincter. Thus it should not be assumed that older patients with ulcerative colitis have weaker sphincters than younger patients. If, despite the urgency and frequency of defecation associated with ulcerative colitis, older patients affirm before operation that they are continent, we believe that they are likely to remain continent after restorative proctocolectomy provided that care is taken not to weaken the sphincter in the course of the operation and that a capacious and compliant rectal substitute is provided.

The best way to preserve the full function of the anal sphincter in our opinion is to avoid stripping its mucosal lining and to anastomose the pelvic reservoir end to end to the top of the anal canal, rather than endoanally. Mucosal proctectomy, by contrast, in which full thickness ileum is anastomosed to the anus within the sphincter at the dentate line, seems from first principles more likely to impair the function of the sphincter, and in fact has been shown in several studies to decrease maximum resting anal pressure, although the magnitude of that decrease has varied between studies. ${ }^{141314}$ In a recently published randomised trial of hand sewn ileoanal anastomosis with mucosectomy $v$ stapled anastomosis without mucosectomy, although the maximum resting anal pressure was significantly decreased after sutured endoanal ileoanal anastomosis when compared with a stapled anastomosis, this did not seem to adversely influence the functional outcome. ${ }^{15}$ It was concluded that a full mucosectomy does not compromise function and that surgical removal of the disease is more complete, this continues to be the view held by the Mayo clinic group. ${ }^{16}$ Our philosophy differs from theirs on this point. We showed previously that preservation of the entire anal canal in the course of restorative proctocolectomy by means of an end to end stapled anastomosis 1-2 cm above the dentate line resulted in higher sphincter pressures, better anal sensation, and significantly better clinical results than we found after mucosal stripping and endoanal, ileoanal anastomosis. ${ }^{4}$ These findings are supported by the clinical results reported by Martin et al with regard to the critical level of the ileoanal anastomosis." 
Hence, if stripping of the anal mucosa with endoanal anastomosis is used in older patients, we think that it is more likely to lead to lower anal pressures and faecal leakage after operation than the technically simpler alternative of end to end anastomosis.

The findings of the present study lend further support to the concept that the entire anal canal should be preserved. The 36 patients who underwent paired physiological tests of anal motor, sensory, and reflex function before and a median of 12 months after operation were typical of patients who undergo elective restorative proctocolectomy for ulcerative colitis worldwide. The clinical results were admittedly slightly inferior in the older patients than in the younger ones, but any differences were small and not statistically significant. Bowel frequency, for example, was little greater in the older patients than in the younger ones. Nine patients experienced minor leakage, six of whom were over the age of 50; such leakage, however, was of mucus only and of minor degree in five of the six patients, and the sole patient who experienced minor faecal leakage was assessed within six months of operation and has in fact improved after longer follow up. Finally, none of the 36 patients experienced leakage that was severe enough to necessitate the wearing of a pad.

We conclude that age itself is not a contraindication to the performance of restorative proctocolectomy with pouch-anal anastomosis. Rather, each patient should be assessed individually before operation with respect to his or her general fitness for major surgery, motivation to avoid an ileostomy, and clinical function of the anal sphincter. Adequacy of anal sphincteric function should then be confirmed by means of laboratory tests of anal pressure and sensation. The case for such objective assessment before operation seems particularly strong in women over the age of 50 because they may have suffered occult damage to the anal sphincter during childbirth and could be at particular risk of a poor functional outcome if the sphincter were to sustain further damage at the time of operation. Patients who give a history of previous anal fistula or abscess represent another subgroup in whom objective measurement of anal sphincteric function before operation is essential. Provided then that function of the anal sphincter is confirmed to be normal before operation and is kept normal at operation by preservation of the entire anal sphincter, we suggest that age alone should not be regarded as an absolute contraindication to the use of restorative proctocolectomy. Patients over the age of 50 who are relatively 'fit' need not be denied the benefits of conservative, sphincter saving surgery.

This paper was presented to the Annual Meeting of the British Society of Gastroenterology, 25-27 September 1991.

1 Metcalf AM, Dozois RR, Kelly KA, Beart RW, Wolff BG Ileal 'J' Pouch-anal anastomosis. Clinical outcome. Ann Surg 1985; 202: 735-9.

2 Neal DE, Williams NS, Johnston D. Rectal, bladder and sexual function after mucosal proctectomy with and without a pelvic reservoir for colitis and polyposis. $\mathrm{Br} \mathcal{F}$ Surg 1982; 69: 599-604.

3 Nasmyth DG, Johnston D, Godwin PGR, Dixon MF, Smith A, Williams NS. Factors influencing bowel function after A, Willams NS. Factors influencing bowel function after

4 Johnston D, Holdsworth PJ, Nasmyth DG, Neal DE Primrose JN, Womack N, Axon ATR. Preservation of the
Pronston D, Holdsworth PJ, Nasmyth DG, Neal entire anal canal in conservative proctocolectomy for ulcerative colitis: a pilot study comparing end-to-end ileo-ana anastomosis without mucosal resection with mucosal proctectomy and endo-anal anastomosis. BrF Surg 1987; 74: $940-4$.

5 Johnston D, Williams NS, Neal DE, Axon ATR. The value of preserving the anal sphincter in operations for ulcerative colitis and polyposis: a review of twenty two mucosal proctectomies. Br F Surg 1981; 68: 874-8.

6 Nicholls RJ, Pezim ME. Restorative proctocolectomy with ileal reservoir for ulcerative colitis and familial adenoileal reservoir for ulcerative colitis and familial adenoBrf Surg 1985; 72: 470-4.

7 Utsunomiya J, Iwama $T$, Imajo $M$, Matsuo $\mathrm{S}$, Sawai $\mathrm{S}$, Yaegashi $\mathrm{K}$, et al. Total colectomy, mucosal protectomy and ileo-anal anastomosis. Dis Colon Rectum 1980; 23 . $459-66$

8 Roe AM, Bartolo DCC, Mortensen NJMcC. New method for assessment of anal canal sensation in various anorectal disorders. BrF Surg 1986; 73: 310-2.

9 Keighley MRB, Henry MM, Bartolo DCC, Mortensen NJMcC. Anorectal physiology measurement: report of working party. BrF Surg 1989; 76: 356-7.

10 Cohen L, Holliday M. Statistics for Social Scientists. London: Harper and Row, 1982.

11 Pescatori $M$, Mattana C. Factors affecting anal continence after restorative proctocolectomy. Int $\mathcal{F}$ Color Dis 1990; 5: 213-8.

12 Bannister JJ, Abouzekry L, Read NW. Effect of aging on anorectal function. Gut 1987; 28: 353-7.

13 Nicholls RJ, Belliveau P, Neill M, Wilks $M$, Tabaquali S Restorative proctocolectomy with ileal reservoir: a pathophysiological assessment. Gut 1981; 22: 462-8.

14 Everett WG. Experience of restorative proctocolectomy with ileal reservoir. Brf Surg 1989; 76: 77-81.

15 Seow-Choen, Tsunoda A, Nichols RJ. Prospective randomised trial comparing anal function after handsewn Ileo-ana anastomosis with mucosectomy versus stapled ileo-ana anastomosis without mucosectomy in restorative proctocolectomy. Brf Surg 1991; 78: 430-4.

16 Kelly KA. Anal sphincter saving operations for chronic ulcerative colitis. Am $\mathcal{F}$ Surg 1992; 163: 5-11.

17 Martin LW, Torres AM, Fischer JE, Alexander F. The critical level for preservation of continence in the ileo-anal anastomosis. Fournal of Pediatric Surgery 1985; 20: 664-7. 